\title{
Natural history of neustonic animals in the Sargasso Sea: reproduction, predation, and behavior of Glaucus atlanticus, Velella velella, and Janthina spp.
}

\author{
Rebecca R. Helm ${ }^{1}$ (D)
}

Received: 9 March 2021 / Revised: 4 August 2021 / Accepted: 12 August 2021 / Published online: 14 December 2021

(c) The Author(s) 2021

\begin{abstract}
The Sargasso Sea, located in the North Atlantic subtropical gyre, is one of the most well-known ocean surface ecosystems on the planet. It supports numerous ecologically and economically important fish species, juvenile turtles, and endemic species. However, in addition to the floating algae Sargassum from which the sea derives its name, numerous floating neustonic animals also live at the surface, yet their basic natural history remains poorly known. Without the basic knowledge of these species, understanding ecosystem function, food webs, and pollution impacts is impossible. This is especially problematic because pollutants like plastic are now increasing at the surface at alarming rates. This study examines the diet, reproduction, and behavior of four neustonic animal species: Velella velella, Janthina janthina, Janthina pallida, and Glaucus atlanticus. All mollusk species showed unique predatory preferences and behaviors, indicating possible methods of niche partitioning among these species. For example, Glaucus atlanticus showed an equal preference for all prey but preyed primarily by crawling below to consume the underside of prey, while large $J$. janthina often preyed more on the margin of $V$. velella and P. physalis, in contrast, J. pallida only preyed on V. velella. Of the four species observed, two reproduced in the lab $(G$. atlanticus and $V$. velella), and the embryo cases of $J$. pallida were examined from both collected snails and discarded bubble rafts. High fecundity rates were observed in all species, which may be an adaptation to high loss rates. This study lays the groundwork for future research on neustonic animals in the Sargasso Sea.
\end{abstract}

Keywords Neuston $\cdot$ Pleuston $\cdot$ Sargassum $\cdot$ Physalia $\cdot$ Habitat

\section{Introduction}

Organisms that live on the ocean's surface-termed neuston (or sometimes pleuston) - are adapted to survive in this razor-thin environment. Concentrated neustonic life is the foundation of the Sargasso Sea: a floating ecosystem in the North Atlantic subtropical gyre. The Sargasso Sea is named after the floating neustonic Sargassum algae (Trott et al. 2011; Pendleton et al. 2014) and serves as a haven for biodiversity in the open ocean. The Sargasso Sea is also a nursery ground for a variety of threatened and endangered organisms (Trott et al. 2011).

Communicated by D. Maggioni

Rebecca R. Helm

rrhelm@gmail.com

1 University of North Carolina Asheville, Asheville, NC, USA
Neustonic animals likely play an important role in the ecology of the Sargasso Sea. Neustonic animals include a variety of cnidarians, (the most prominent cnidarians are Velella, Physalia, and Porpita), mollusks (Janthina snails and Glaucus nudibranchs), and crustaceans (barnacles, copepods, shrimp, and isopods), among other organisms like fish larvae and open-ocean insects (Helm 2021). Many neustonic animals possess special buoyancy structures that allow them to remain at the surface and most are blue or purple to blend into the surface habitat. Neustonic species often have little control over their direction of movement and instead rely on the wind and currents for transport. This lack of mobility may concentrate neustonic animals within the Sargasso Sea, like the neustonic algae Sargassum.

A wide variety of predators rely on neustonic animals. Neuston are important prey for turtles (Witherington 2002; Parker et al. 2003; Wedemeyer-Strombel et al. 2015), diverse seabirds (Harrison et al. 1983), and a variety of fish species (see review in (Helm 2021)). Neuston in turn consume 
pelagic prey like copepods, fish eggs and larvae, and gelatinous zooplankton (Bieri 1961, 1970; Purcell 1984; Purcell et al. 2012). And pelagic life cycle stages of some neustonic animals may further trophically link the surface to deeper water (Helm 2021). However, we know very little about the biology of neustonic animals in general or in the Sargasso Sea in particular. This makes it difficult to assess their role in the health of the Sargasso Sea ecosystem. This is especially true now, as massive amounts of floating plastic become concentrated in this area, occupying the same surface layer where neuston live (Carpenter and K L Smith 1972; Winston 1982; Siuda 2011; Huffard et al. 2014).

In March 2020, the author examined the natural history, including feeding biology, reproductive biology, and behavior, of neustonic animals in the Sargasso Sea (Fig. 1). The author observed species-specific predator-prey interactions, high rates of reproduction that may have evolved to hedge against patchy resources, and unique behaviors producing ephemeral habitat at the surface.

\section{Materials and methods}

\section{General setup}

Neustonic animals are difficult to collect. Many species must be hand-dipped from the water's surface (i.e., G. atlanticus, $P$. physalis), in order to prevent injury. Further, due to the seasonality of the Sargasso Sea, neustonic animals are observed in Bermuda most often in early spring (Kaitlin Noyes, personal communication 2020).

All animals were collected around Bermuda during 2 halfday expeditions in early March 2020. Animals were found either by looking for surface slicks in open water or in coves by searching in debris-concentrated areas. All animals were dipped from the water's surface using buckets or handheld containers. Prior to capture, Physalia sp. were agitated by repeatedly scooping and releasing them until all tentacles were contracted before finally being collected. All animals were housed in large outdoor seawater bins at the Bermuda Institute of Ocean Sciences (BIOS) or in 5-gallon buckets of still seawater. For experiments and observations, animals were placed in a clear $20 \times$ $20 \times 20$-cm tank filled with water either collected at the time of animal collection or from the BIOS flow-through seawater system. All illumination was generated either by ambient sunlight, overhead lights, or Viltrox RB08 LED lights. All microscopy was done using a dissecting microscope. All photographs and video were recorded using an Olympus Tough TG-5 camera.

\section{Feeding trials}

To determine prey selectivity for Glaucus atlanticus, Janthina pallida and Janthina janthina, healthy Velella vele$l l a$, and Physalia sp. were gently nudged to contact the oral region and, in the case of $G$. atlanticus, the cerata. The response of predators was then observed and interactions were documented with photographs and video.
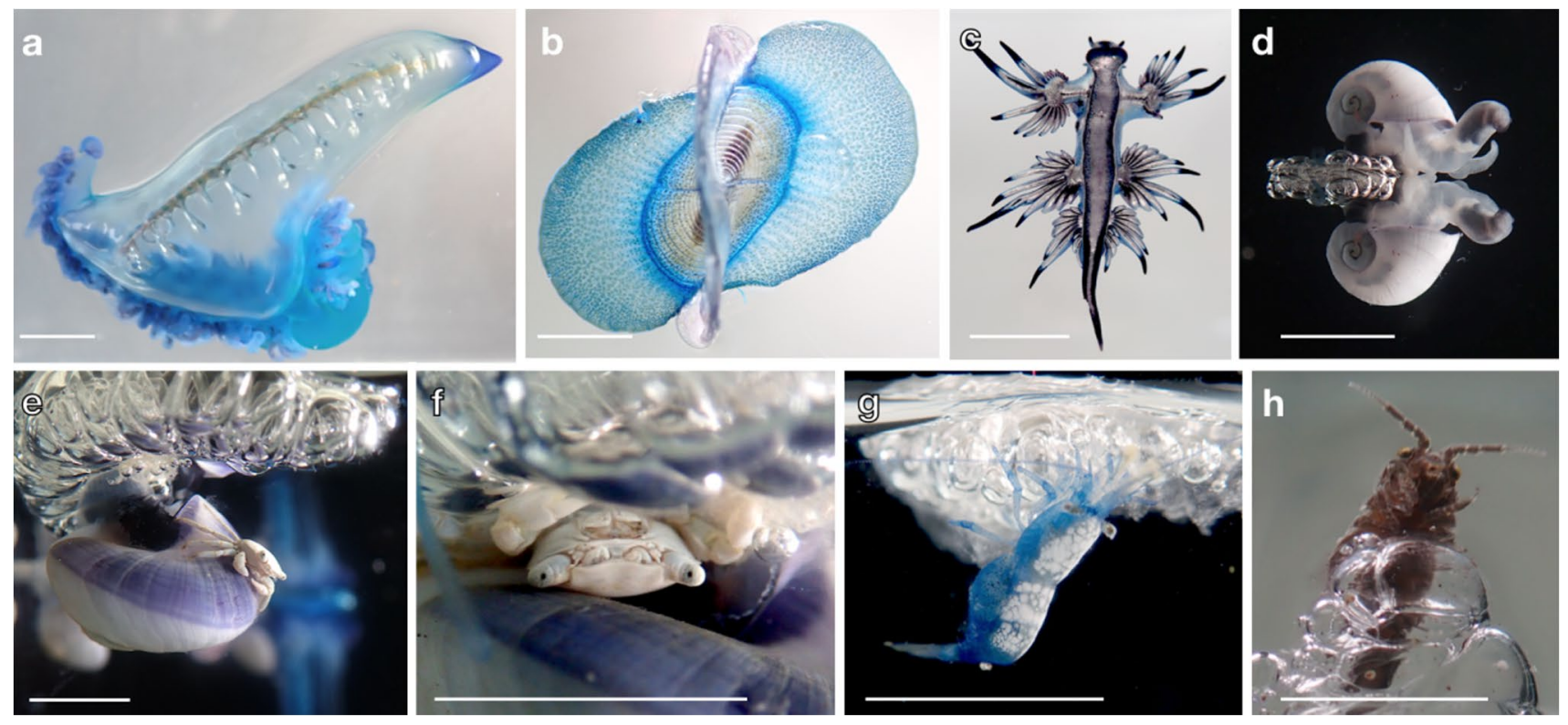

Fig. 1 Neustonic animals collected around Bermuda in March of 2020. a Physalia sp.; b Velella velella; c Glaucus atlanticus; d Janthina pallida; e Janthina janthina; f commensal crab Planes sp. col- lected on a J. janthina; g neustonic shrimp Latreutes sp. on an abandoned Janthina sp. raft; $\mathbf{h}$ neustonic isopod Idotea metallica on an abandoned Janthina raft. Scale bars: $1 \mathrm{~cm}$ for all 


\section{Reproduction trials}

\section{Glaucus atlanticus}

Glaucus atlanticus has been reported to both liberate fertilized embryo strings into the water column (Huang et al. 2017) and to affix them to prey (mentioned in Thompson and McFarland 1967). To determine the rate of embryo production and whether or not the collected $G$. atlanticus would lay on a substrate, both the G. atlanticus and a small live $V$. velella were placed into a finger bowl containing $250 \mathrm{ml}$ of seawater from 11:50 p.m.-11:50 a.m. Egg string location and number were recorded at the end of the time trial. Glaucus atlanticus produced egg strings at a similar minute rate compared to the average for the total trial, suggesting egg string production was consistent.

\section{Velella velella}

Two methods were used to determine the production rate of medusae for $V$. velella. First, freshly collected polyps were placed in finger bowls with approximately $250 \mathrm{ml}$ seawater and allowed to liberate medusae for $11 \mathrm{~h}$. However, many medusae appeared small and underdeveloped, consistent with a stress response, so a second trial was performed. Freshly collected polyps were placed in the same condition and allowed to liberate medusae for $1 \mathrm{~h}$. For both trials, the total number of medusae produced over the full time was measured, and the rate of production over $1 \mathrm{~h}$ and $11 \mathrm{~h}$ was calculated. Because many fewer medusae were produced for the 1-h time trial compared to the per-hour rate over $11 \mathrm{~h}$, this gives us a range of the possible number of medusae produced over a $11 \mathrm{~h}$ period.

\section{Janthina pallida}

Multiple free-floating $J$. pallida rafts with eggs were collected at sea or from animals in the lab. The number of embryo cases was counted for two rafts found at sea. The number of embryos in embryo cases was also counted for one raft of an animal that liberated a raft in the lab, focusing on a range of embryo cases from the least to the most mature. The total number of embryos per raft was estimated by multiplying the average number of embryos per case by the total number of egg cases per raft.

\section{Behavior}

All adult animals were observed in a $20 \times 20 \times 20$ glass photo tank. For J. pallida and V. velella embryos and medusae (respectively), their behavior and buoyancy were recorded over several days. For buoyancy estimates, larvae of $J$. pallida were observed in a vertically oriented glass pipette column. After the time trials, $V$. velella medusae were placed in a 3.8-L flat-sided fishbowl (Petco 1 Gallon Deluxe Plastic Drum Betta Bowl) with an air stone, creating a circular flow to keep medusae off the bottom, with a HQRP 225 LED Blue + Red Indoor grow light placed roughly 15 $\mathrm{cm}$ from the bowl for illumination. To observe medusa gravitropic responses, the air stone was removed, and the behavior of medusae was recorded during daylight hours.

\section{Results}

\section{Feeding trials}

\section{Glaucus atlanticus}

A single Glaucus atlanticus was collected and responded to and ate both Physalia sp. and V. velella (Fig. 2a-c). For V. velella, G. atlanticus used cerata to "hold onto" and manipulate prey, moving the $V$. velella to find fresh tissue. Although $G$. atlanticus ate all parts of the small $V$. velella, on several larger polyp, the $G$. atlanticus first bit the margin, and then if it was not repelled (see Behavior), ate the more protected zooids below the mantel (Fig. 2a, b). During feeding on a $V$. velella, slight squeaks and scraping noises could be heard emanating from the G. atlanticus, the squeaks may have been from air escaping the gut and scraping noises from the radula grinding against the $V$. velella float. For Physalia sp., G. atlanticus climbed down the Physalia sp. below the surface to feed on zooids (Fig. 2c). Physalia sp. produced copious amounts of mucous while being preyed upon, possibly as a deterrent.

\section{Janthina janthina}

Multiple Janthina janthina were collected and exhibited generalist tendencies. Janthina janthina fed on both $V$. velella and Physalia sp. (Fig. 2d).

\section{Janthina pallida}

Multiple Janthina pallida were collected. Specimens rested upon the ocean's surface with their proboscis out and flanked by two "wings" (Fig. 2e, left animal). When they came into contact with $V$. velella, they lashed out rapidly, grabbing clusters of dactylozooids or pieces of the mantle (Fig. 3, Online Resource 1). On several occasions, J. pallida bit a number of zooids or the mantle but then released the $V$. velella to swallow the flesh. In one instance, J. pallida appeared to remain close to the $V$. velella, but in three additional feeding attempts, J. pallida were not able to stay within close proximity long enough to eat more than 2-3 bites (see Behavior: Velella velella). 

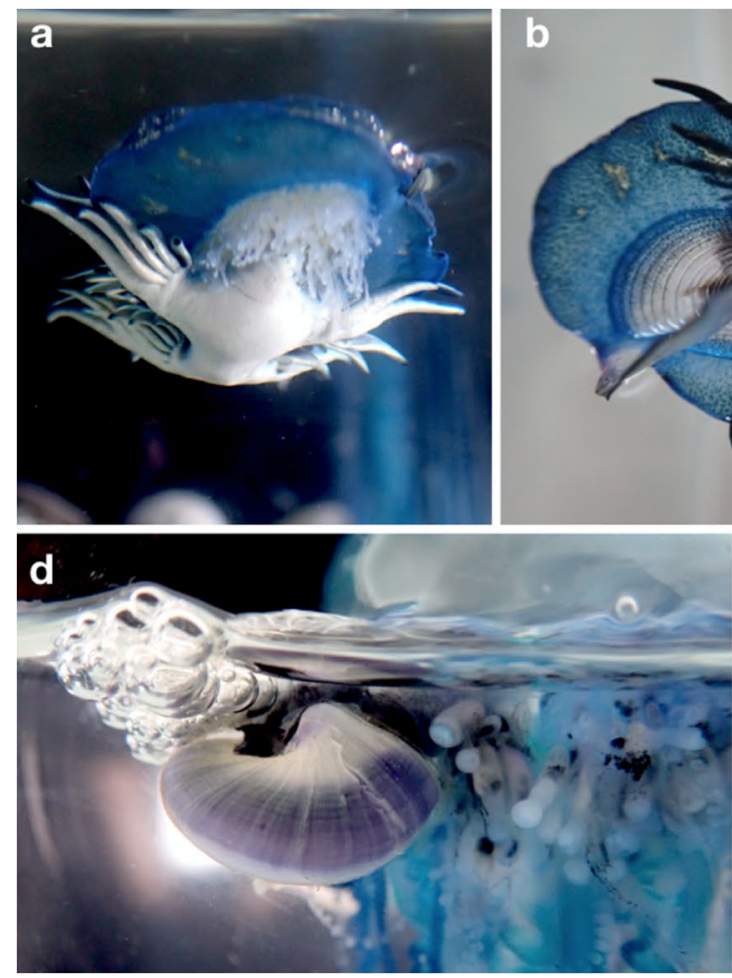
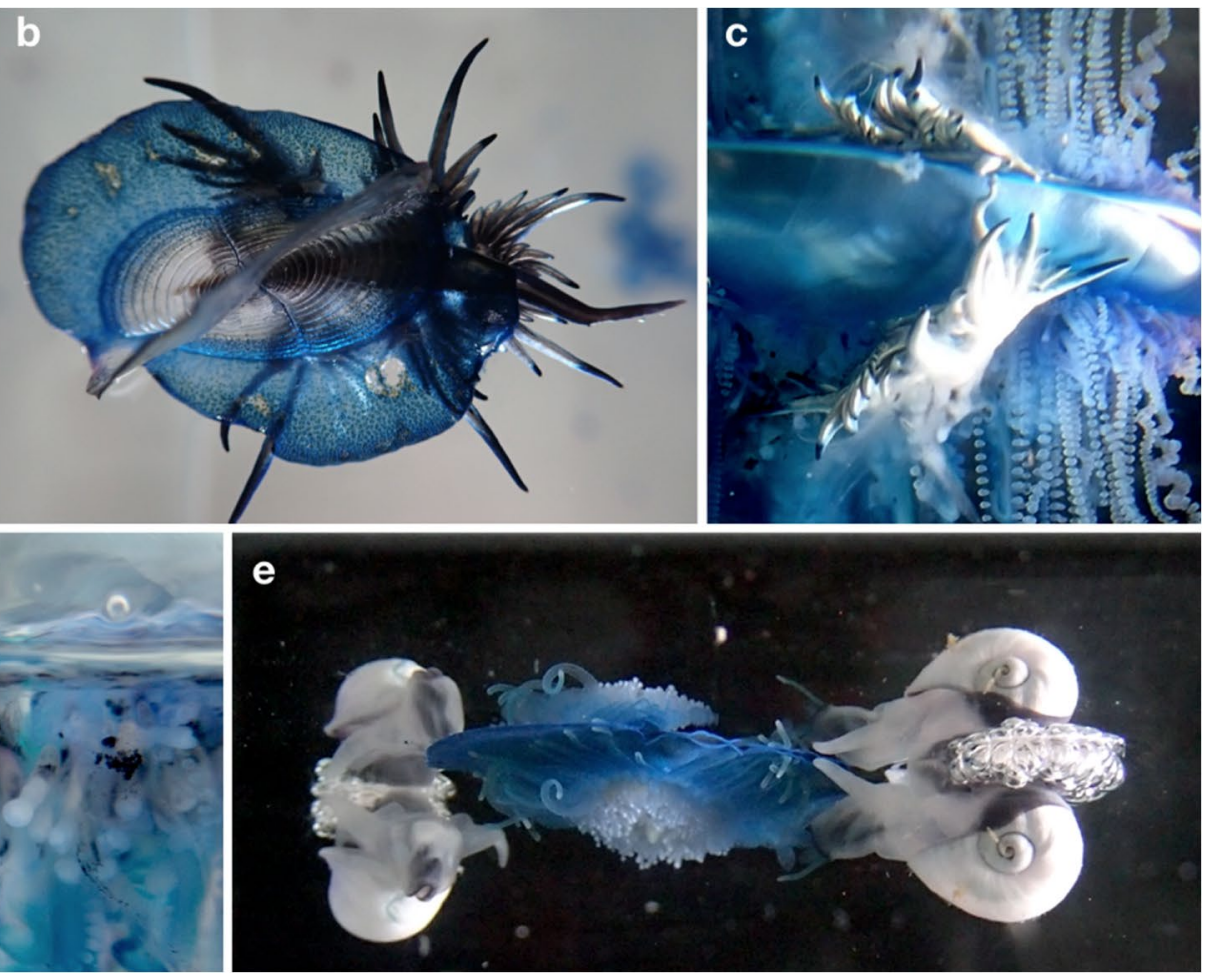

Fig. 2 Neuston feeding behavior. a Glaucus atlanticus feeding on the central gastrozooid of a Velella velella; $\mathbf{b}$ G. atlanticus feeding on a $V$. velella as seen from above; c $G$. atlanticus climbing below a
Physalia sp. to feed on zooids; $\mathbf{d} J$. janthina feeding on a $P$. physalis at the surface; e J. pallida feeding on a the margins of a $V$. velella

11:50 a.m. to ensure the rate of embryo production was consistent; 52 embryo strings were produced at that time. From 11:50 p.m. to 11:00 a.m., a total of 606 embryo strings were produced, and over the $12 \mathrm{~h}, 658$ embryo strings were produced, for an average of 55 egg strings per hour. This suggests $G$. atlanticus produced a consistent number of embryo strings through the trial. An average of 16.06 embryos was present per string ( $n=50,+/-2.74 \mathrm{sd}$ ). Combined, this G. atlanticus produced roughly 10,567 embryos over $12 \mathrm{~h}$ (Table 1).

All embryos appeared to develop synchronously within each string, though embryos were not synchronized between strings (Fig. 4a). All observed newly liberated strings contained zygotes (Fig. 4a, b), with the first cleavage initiating 2-3 $\mathrm{h}$ after liberation. This suggests eggs are fertilized just prior to liberation.

\section{Janthina pallida}

Multiple $J$. pallida rafts were collected either at sea without snails or from animals collected with cases. Large egg cases with late-stage embryos were more abundant at one end, while small egg cases with early-stage embryos were more abundant at the opposite end (based on images uploaded on iNaturalist.org of Janthid rafts and snails, it appears 

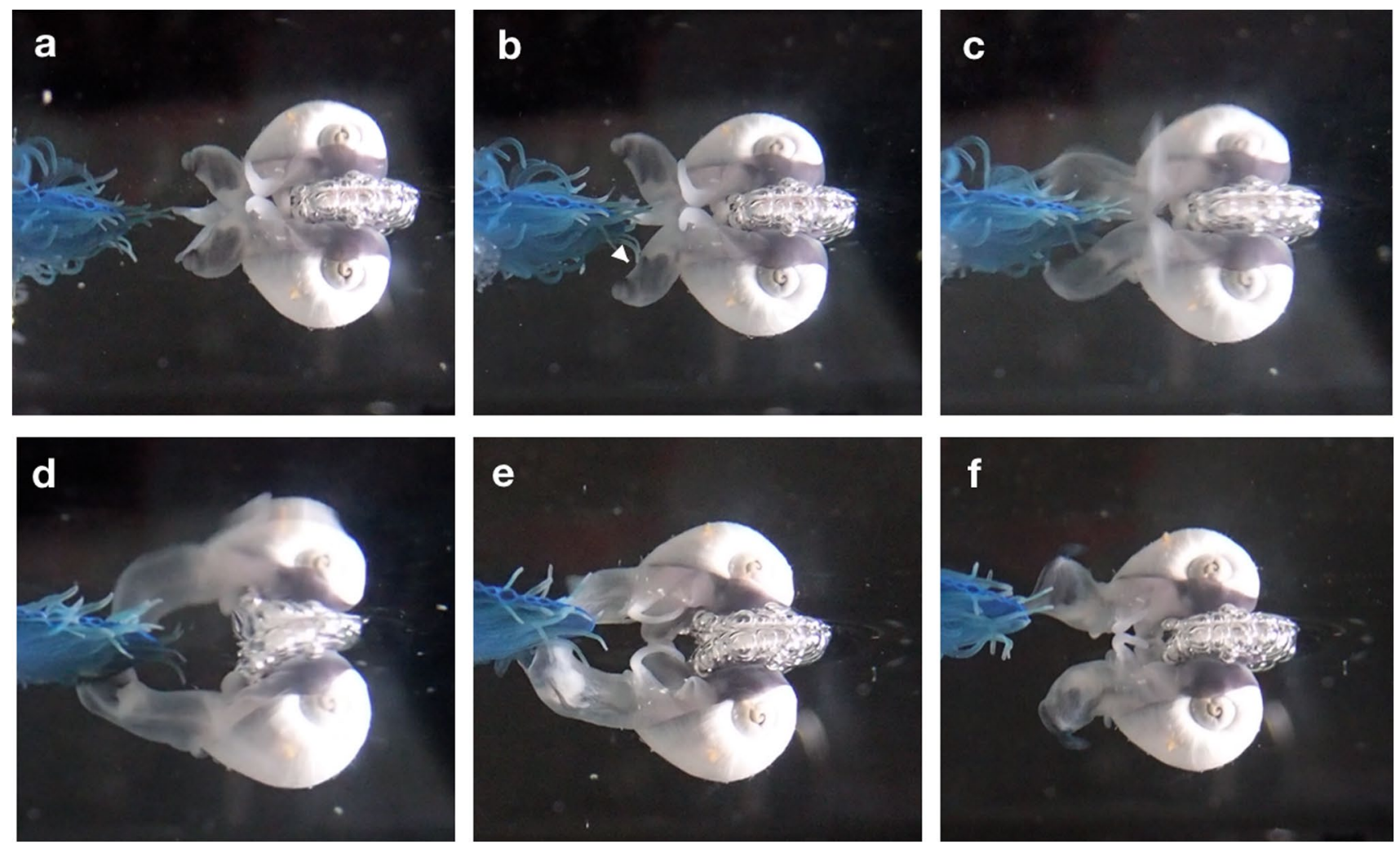

Fig. 3 Janthina pallida striking prey. From top left to the bottom right: a J. pallida near but not touching Velella velella; b contact between $J$. pallida and $V$. velella (white arrow); $\mathbf{c}$ and $\mathbf{d}$ strike occurring in less than a second followed by $\mathbf{e}$ feeding and $\mathbf{f}$ eventual release

Fig. 4 Embryonic and pelagic stages of select neuston.

Neuston life cycles connect the surface to deeper layers: a Glaucus atlanticus zygotes in a vertical egg string and two-cell stage embryos in the horizontal egg string; b Glaucus atlanticus blastulae; c Veliger larvae of Janthina pallida; d Velella velella medusae. Scale $\mathbf{a}, \mathbf{b}$, and c: 100 um; d: $1 \mathrm{~mm}$
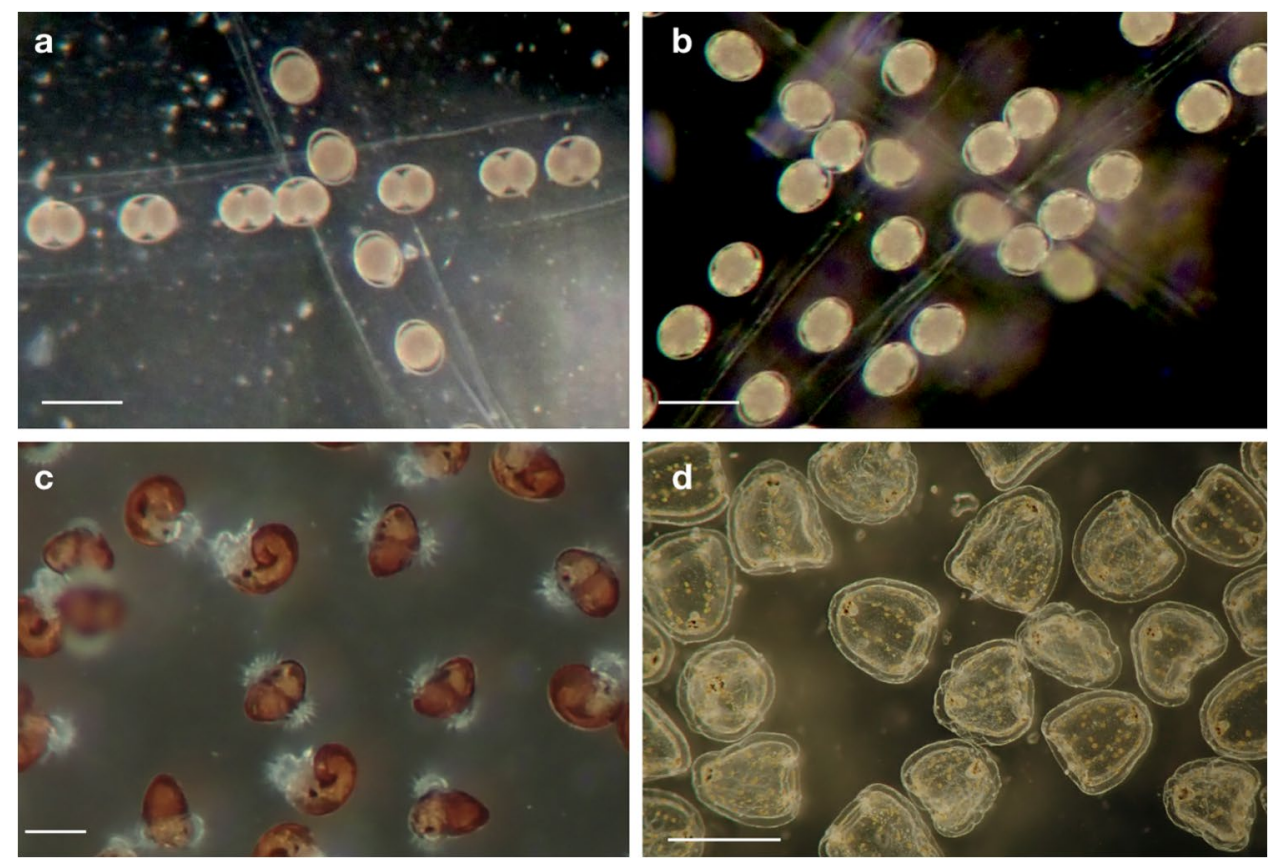

that the most mature egg cases are the farthest away from the snail aperture, suggesting that snails deposit egg cases while continuing to build rafts, though this is unclear for
$J$. pallida specifically.) The size of egg cases ranged from 2.1 to $3 \mathrm{~mm}$, with an average of 126 egg cases per raft ( $n$ $=6,+/-35 \mathrm{sd}$, Online Resource 2) and 358 embryos per 
Table.1 Reproductive output for three neustonic species

\begin{tabular}{lll}
\hline Species (trial) & $\begin{array}{l}\text { Mean reproductive output per hour } \\
( \pm \mathrm{sd})\end{array}$ & $\begin{array}{l}\text { Number of embryos } \\
\text { per string/case }( \pm \text { sd })\end{array}$ \\
\hline Velella velella $(11-\mathrm{h}$ trial $)$ & $43.0( \pm 7.6)$ medusae & NA \\
Velella velella $(1-\mathrm{h}$ trial $)$ & $3.1( \pm 1.3)$ medusae & NA \\
Glaucus atlanticus & 880.6 embryos & $16.1( \pm 2.7)$ embryos \\
Janthina pallida & NA & $358( \pm 84)$ embryos \\
\hline
\end{tabular}

case ( $n=13,+/-84$ sd, Online Resource 2 ). Multiplying the average number of cases per raft by the average number of embryos per case results in 45,108 embryos per raft. Embryos hatched into small mobile veliger larvae (Fig. 4c).

\section{Velella velella}

Velella velella produced large numbers of medusae (Fig. 4d). Medusae were small: $1 \mathrm{~mm}$ in diameter with a diminutive manubrium and patches of symbiotic zooxanthellae. After the 11-h trial, $V$. velella produced an average of 1017 medusae $(n=5,+/-167 \mathrm{sd})$ or $473(n=5,+/-84 \mathrm{sd})$ medusae per $1 \mathrm{~cm}$ of float. In the 1 -h trial, animals produced an average of 7 healthy medusae $(n=4,+/-3.7 \mathrm{sd})$ or 3.1 medusae per centimeter of float (Online Resource 2).

\section{Behavior}

\section{Janthina spp.}

In captivity, snails continued to build bubble rafts (Fig. 5), and the rafts of the two species were distinguishable by their differences in shape and bubble density (Fig. 6). The rafts of $J$. janthina were easy to date because newly collected animals had large amounts of dried foam adhered to the bubbles. But within $48 \mathrm{~h}, J$. janthina rafts consisted almost completely of new bubbles. To make rafts, J. janthina dipped their anterior foot into the air to capture a bubble, which they coated in mucous and adhered to the raft. One animal was observed to finish constructing a new portion of its raft by pressing its foot firmly against the raft and sliding it back and forth over the newly adhered bubbles as if to further cement and smooth them into place before finally resting motionless (Fig. 5, Online Resource 3).

Several free-living animals were observed using snailoccupied rafts and free-floating unoccupied rafts. Janthina janthina were collected with flotsam crabs (Planes sp.) adhering to their rafts and taking shelter between the raft and the snail itself (Fig. 1e, f). A blue shrimp (likely Latreutes fucorum) was collected clinging to a discarded J. pallida raft (Fig. 1g). In addition, the surface-dwelling isopod Idotea metallica was collected unfixed to any floating object but would rest on Janthina rafts in the laboratory (Fig. 1h).

When antagonized, snails of both species released a purple "dye" into the water (Fig. 6c). This dye quickly changed to brown as it sank, and when placed on a cotton cloth, it bleached in the sun. However, when placed on cotton cloth in the dark, it dried and stained the cloth a deep purplebrown color. The dye was only secreted during handling or in the case of $J$. pallida, after retracting into the shell when
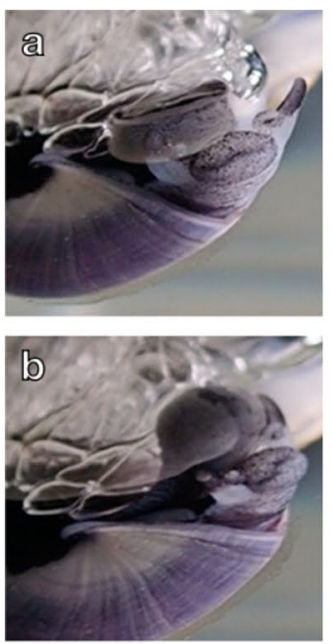

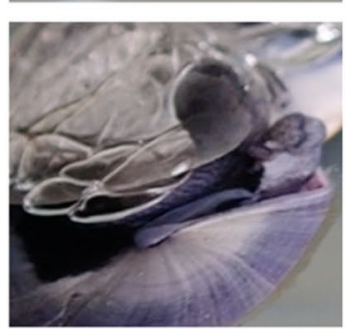

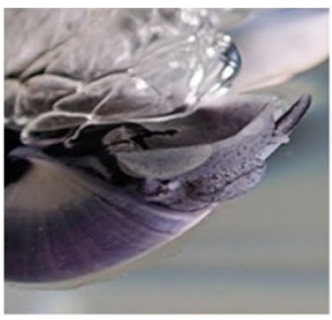
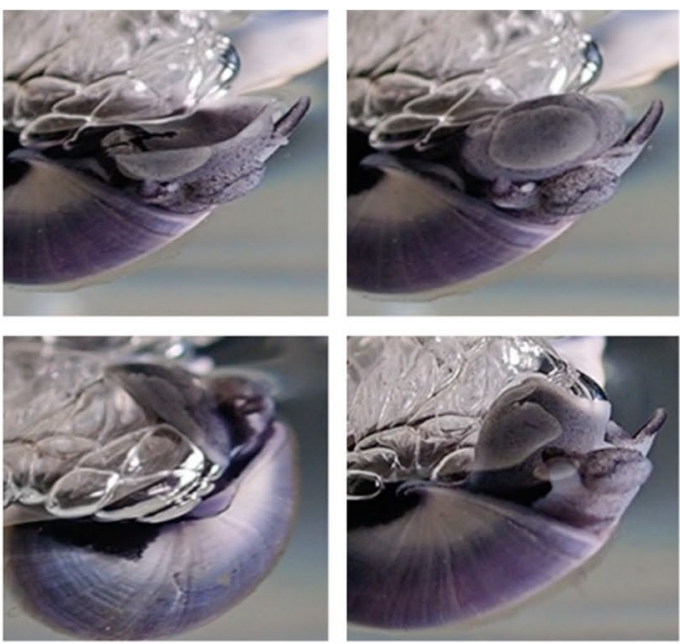

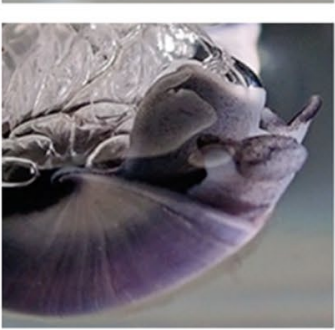

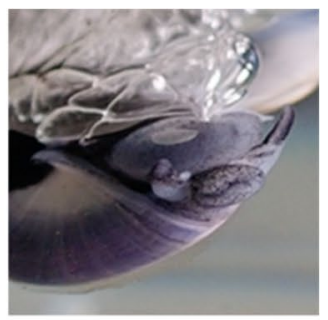

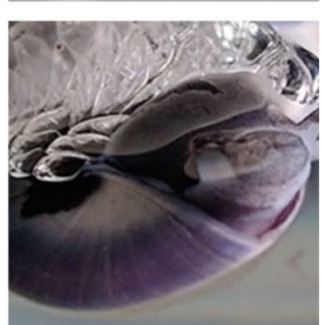

Fig. 5 Janthina janthina constructing a bubble raft. From the top left to the bottom right: a J. janthina extends its foot on the surface and curls around an air pocket and then adheres the bubble to the raft.
Many bubbles can be added in this way; $\mathbf{b}$ After adding a number of bubbles, J. janthina smooths over the surface of the raft where new bubbles were added before resting 

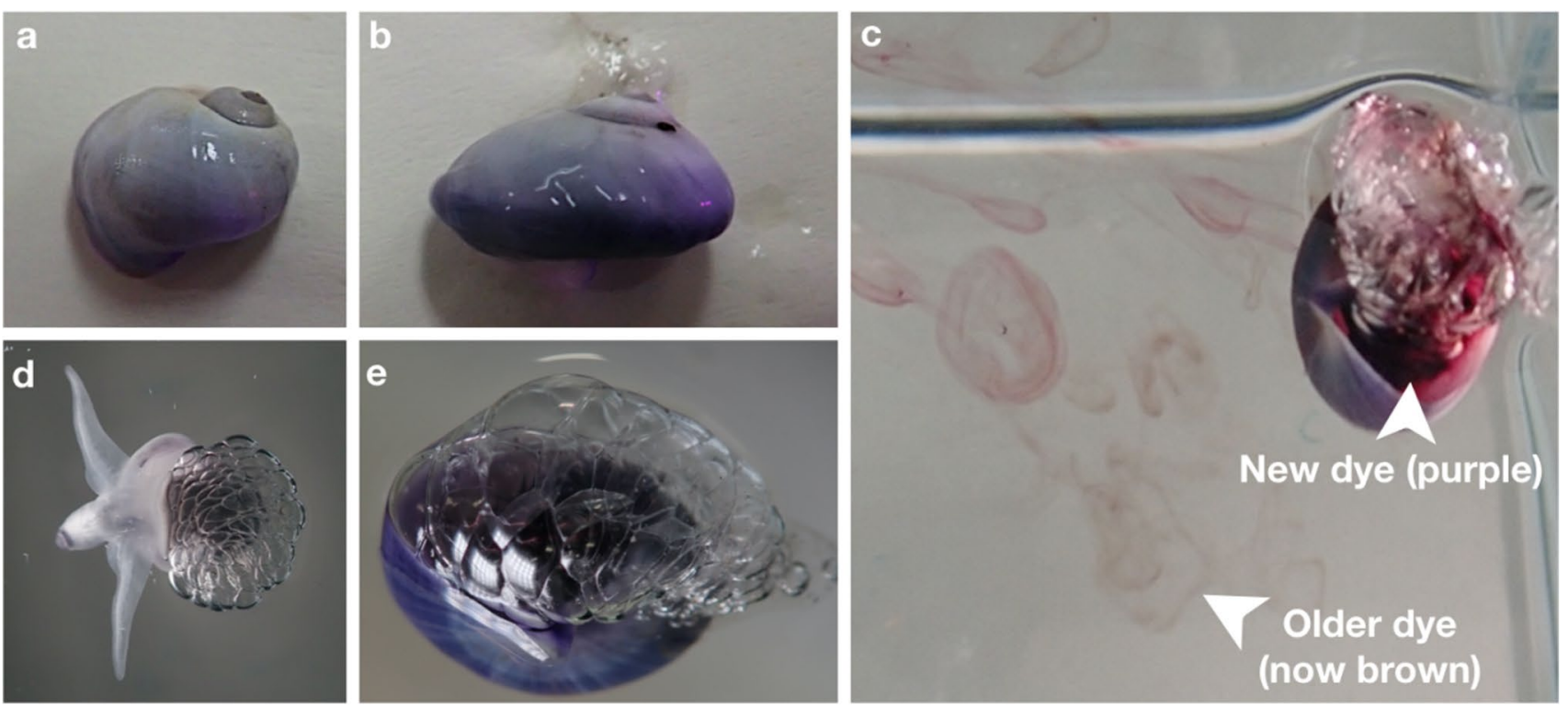

water; $\mathbf{d}$ Janthina pallida bubble raft with many small bubbles at high

Fig. 6 Features of Janthids collected near Bermuda. a Janthina pallida shell; b Janthina janthina shell; c Janthina janthina secreting dye, which rapidly turns brown as it leaves the shell and enters the

presented with a Physalia sp. during feeding trials (which it did not attempt to eat).

Newly hatched J. pallida veliger larvae did not display clear phototaxis but showed evidence of possible sinking behavior (Online Resource 4).

\section{Velella velella}

Velella polyps pulsed rhythmically. The internal feeding and reproductive zooids pulsed in coordination at a higher frequency than the surrounding tentacles, which also pulsed in unison periodically (Online Resource 5). After being bitten by a $J$. pallida, V. velella appears to produce an unknown clear substance on the water's surface, so that subsequent attempts to move $V$. velella and J. pallida into close contact were unsuccessful (Online Resource 6). When moving a $V$. velella toward a J. pallida, the J. pallida was "pushed" away by the $V$. velella. A possible hydrophobic compound or mucus barrier may have been secreted by $V$. velella. When a J. pallida was physically pushed through this barrier with a pipette tip, it kept feeding on the $V$. velella, suggesting the physical barrier may be a rapidly deployed anti-predator defense.

Newly liberated medusae in both medusa trials sank to the bottom of the finger bowl and did not appear to swim. However, after 2-3 days in the fishbowl, all medusae swam actively. When the air stone was removed, and the water flow became still; medusae swam actively to the water's surface (Online Resource 7). density; e Janthina janthina bubble raft with few large bubbles of low density

\section{Discussion}

\section{Dietary niche separation}

Floating marine organisms occupy an incredibly narrow habitat range with little control over their direction of movement; for most species, prey is not pursued but encountered haphazardly. Dietary specialization of closely related species may allow different species to co-occur in this environment without competition (Bieri 1966, 1970). This is the first study to show evidence for niche partitioning of neustonic mollusks in the Sargasso Sea. Despite co-occurring in the same region, J. pallida and J. janthina appear to prefer different prey. While J. janthina preyed upon Physalia sp. and V. velella, J. pallida appears behaviorally adapted to prey on $V$. velella and did not prey upon Physalia sp. These results are similar to those by Bieri (1966), who observed that $J$. prolongata in the eastern North Pacific prefer $V$. velella and P. porpita but do not prey upon Physalia sp.

For both G. atlanticus and Janthina spp., consuming only part of a prey item was more common than full consumption. Both J. pallida and J. janthina preyed largely on the margins of their prey, which is consistent with observations by Bieri for J. prolongata (Bieri 1966). While G. atlanticus preyed upon both species of cnidarians, unlike J. pallida and $J$. janthina, it also often crawled under prey to feed on central zooids. Bieri (1966) also observed Glaucus much more actively feeding on gastrozooids compared to margin tissue. 
Differences between Janthina and Glaucus in the region of prey on which they feed may create further niche partitioning. This difference may be due to differences in the floating mechanism or prey defense. Glaucus atlanticus holds swallowed air in its stomach (Lalli and Gilmer 1989), while Janthids build bubble rafts and cannot swim (Wilson 1956). This makes crawling under prey considerably riskier for Janthids. Differences in the prey region consumed may also be due to defenses by $V$. velella and Physalia. After being attacked by $J$. pallida, V. velella appeared to produce a mysterious antipredator barrier that prevented J. pallida from getting close again. While this may inhibit Janthids from prolonged feeding, G. atlanticus can "grab" onto prey using cerata, potentially rendering these barriers less effective. For these reasons (and likely others), G. atlanticus is able to take advantage of central zooids that it must crawl underneath to eat, while Janthids may be more likely to prey upon the margins. However, these results should also be considered in light of possible ontogenetic shifts. Small Janthinds have been reported to crawl on much larger prey and eat below the margin (Bieri 1966). If they disturb their prey's float or are too heavy for their prey, both will sink. Further work should examine how predation changes over development and across species of different sizes.

\section{Reproduction and implications for connectivity and dispersal}

The surface habitat is distinct from both pelagic and benthic environments, sharing qualities of each but not fully analogous to either. The surface is a barrier, similar to the benthos, but less rigid and with no fixed position. For this reason, animals at the surface likely evolved unique life histories distinct from both benthic and pelagic species. In this study, the reproduction of three neustonic species was examined. Both J. pallida and G. atlanticus produced large numbers of embryos (though only the rate of G. atlanticus was measured), and $V$. velella produced variable numbers of medusae depending on conditions.

All three species observed here have nonmobile surface stages at the mercy of currents, waves, and weather. These species may be aggregated into patchy distributions or spread over large distances. This is a remarkable challenge specifically for predators J. pallida and G. atlanticus, which cannot seek out prey. A high number of larvae for $J$. pallida and $G$. atlanticus suggests a form of reproductive bet-hedging against these uncertain conditions. In fact, $G$. atlanticus has high fecundity compared even to similarly sized benthic eolid nudibranchs (Ross and American 1990). Perhaps unsurprisingly, the rate of embryo production in $G$. atlanticus is dependent on food availability: after several days without food embryo production decreases (Ross and American 1990).
Similar to the species observed here, the European eel (Anguilla anguilla), which migrates to spawn in the Sargasso Sea, also has an extremely high fecundity rate, with millions of eggs being produced by a single eel female (MacNamara and McCarthy 2012). However, this species is still in precipitous decline and listed as critically endangered. High reproduction rates of Sargasso Sea organisms may provide some bet-hedging in undisturbed systems, but they may still be vulnerable to human impacts.

According to Ross and American (1990), embryonic development of $G$. atlanticus takes about 3 days at $19^{\circ} \mathrm{C}$, and larvae have been kept for over a week in captivity before eventually dying without metamorphosis. Their healthy development at $19{ }^{\circ} \mathrm{C}$ is a clue to their oceanic habitat: if G. atlanticus embryos sank below the thermocline before completing embryogenesis, development may require cooler conditions. However, tolerance to sea surface temperatures suggests they can, at least, remain relatively shallow for an extended period. This may also be true for $V$. Velella. Some studies have reported $V$. velella medusae and larvae in deep water (however, they used a net that remained open while descending and ascending (Woltereck 1904)), while others have found medusae near the surface and propose an epipelagic distribution (Larson 1980). The negative gravitropism of several-day-old medusae, observed here, suggests they do occupy the epipelagic, at least during some times of the day or during specific stages of development. This is consistent with the presence of symbiotic zooxanthellae in medusae (Larson 1980), which could provide nutrients in prey-depleted oligotrophic waters. In fact, the mouths of young medusae may not fully develop for several days after liberation (Brinckmann-Voss 1970), resulting in young medusae being reliant on the zooxanthellae for sustenance. Future studies should look for evidence of changes in gravitropism throughout a 24-h cycle and at different ages, as well as the presence of medusae and larvae in samples from different depths.

Janthina pallida larvae are poorly known. Embryos of most Janthids remain affixed to the float through development, tying their fate to ocean surface conditions. However, the potential positive gravitropism of newly hatched veligers observed here suggests they may retreat into deeper water (though perhaps still epipelagic). However, a more focused study of this should be conducted to confirm. Regardless of their larval habitat in the pelagic zone, at some point during development, these planktotrophic larvae return to the surface, possibly aided by a small secreted mucous net or string of bubbles (Wilson 1956; Lalli and Gilmer 1989).

Very little is known about the temporal and spatial dynamics of floating neustonic animals. Some seasonality has been suggested for $V$. velella off the California coast (Bieri 1977), though this may also (or instead) be due to seasonal changes in wind or currents. If neustonic species do 
exhibit seasonality, presumably, $V$. velella and Physalia sp. would recruit ahead of or concurrent with their predators $J$. pallida and G. atlanticus, unless some or all species persist across seasons. And V. velella and J. pallida must be present before any organism that might utilize their floating substrates can proliferate (see section "Habitat construction").

\section{Habitat construction}

Janthina snails may appreciably contribute to floating temporary habitats in the open ocean. The rapid rate of new raft construction and the abandonment of floating unoccupied rafts could aid in larval dispersal and generate substrate for rafting organisms or facultative neuston. One of the two unoccupied rafts collected in this study was being used by a neustonic shrimp, and upon return to the lab, was later utilized by an Idotea metallica isopod. However, these rafts are among the most inconspicuous objects on the high seas: literal collections of bubbles that may go unnoticed even in neuston net samples. Their firm rubbery texture and inflexible movement on the waves are the only things that distinguish them from sea foam.

In addition to floating Janthid rafts, the skeletal floats of $V$. Velella are also buoyant, and neustonic and rafting barnacles settle on them. Although most $V$. velella were not fully consumed, a single $G$. atlanticus cleared a small $V$. velella overnight, with only the floating skeleton remaining. High lethal predation on $V$. velella may create substrates for additional rafting organisms and neuston to use.

\section{Conclusions}

We know very little about the biology and ecology of surface marine life. This study presents new information about the basic biology, predation, reproduction, and behavior of neustonic animal species in the Sargasso Sea.

The Sargasso Sea is a critical habitat in the North Atlantic, including for commercial and endemic species, juvenile turtles, endangered eels, and countless other organisms that utilize this habitat at various times in their life history. Understanding the biology and ecology of neustonic species is critical to our understanding of broader ocean connectivity and food web dynamics. This study suggests that predatory niche partitioning, high fecundity rates, and habitat construction may be important features of neustonic animal biology.

Future research on the spatial and temporal distribution of these species (at all life cycle stages), food web dynamics, and connectivity will further advance our knowledge of surface ecology and floating life in the Sargasso Sea.

Supplementary Information The online version contains supplementary material available at https://doi.org/10.1007/s12526-021-01233-5.
Acknowledgements The author would like to thank the Bermuda Institute of Ocean Sciences, with special thanks to Kaitlin Noyes, Leocadio Blanco-Bercial, Amy Maas, Chris Flook, and Kyla Smith for your generous support. All specimens were collected in Bermuda under Special Permit no. SP200501.

\section{Declarations}

Conflict of interest The authors declare no competing interests.

Ethics approval All applicable international, national, and/or institutional guidelines for the care and use of animals were followed by the authors.

Sampling and field studies All necessary permits for sampling and observational field studies have been obtained by the authors from the competent authorities and are mentioned in the acknowledgements, if applicable.

Data availability All data generated or analyzed during this study are included in this published article and its supplementary information files.

Author contribution RRH conceived of, designed, conducted the research, analyzed the data, and wrote the manuscript.

Open Access This article is licensed under a Creative Commons Attribution 4.0 International License, which permits use, sharing, adaptation, distribution and reproduction in any medium or format, as long as you give appropriate credit to the original author(s) and the source, provide a link to the Creative Commons licence, and indicate if changes were made. The images or other third party material in this article are included in the article's Creative Commons licence, unless indicated otherwise in a credit line to the material. If material is not included in the article's Creative Commons licence and your intended use is not permitted by statutory regulation or exceeds the permitted use, you will need to obtain permission directly from the copyright holder. To view a copy of this licence, visit http://creativecommons.org/licenses/by/4.0/.

\section{References}

Bieri R (1961) Post-larval food of the pelagic coelenterate, Velella lata. Pac Sci 15:553-556

Bieri R (1966) Feeding preferences and rates of the snail, Lanthina prolongata, the barnacle, Lepas anserifera, the nudibranchs, Glaucus atlanticus and Fiona pinnata, and the food web in the marine neuston. Publ Seto Mar Biol Lab 14:161-170

Bieri R (1970) The food of Porpita and niche separation in three neuston coelenterates. Publ Seto Mar Biol Lab 17:305-307

Bieri R (1977) The Ecological significance of seasonal occurrence and growth rates of Velella (Hydrozoa). Publ Seto Mar Biol Lab 18:63-76

Brinckmann-Voss A (1970) Anthomedusae-Athecatae (Hydrozoa, Cnidaria) of the Mediterranean. Fauna Flora Golfo Napoli 39:1-96

Carpenter EJ, K L Smith SJS (1972) Plastics on the Sargasso Sea surface. Science 175:1240-1241. https://doi.org/10.1126/science. 175.4027.1240

Harrison CS, Hida TS, Seki MP (1983) Hawaiian seabird feeding ecology. Wildl Monogr 85:3-71 
Helm RR (2021) The Mysterious Ecosystem of the Ocean's Surface. PLoS Biol 19(4):e3001046. https://doi.org/10.1371/journ al.pbio. 3001046

Huang HD, Chiu WC, Chang MC (2017) (2017) First record of a rare aggregation of the neustonic nudibranch Glaucus marginatus (Mollusca: Gastropoda: Glaucidae) from Kenting National Park, Southern Taiwan. Collect Res 30:17-21. https://doi.org/10.6693/ CAR201712_30(1).0002

Huffard CL, von Thun S, Sherman AD et al (2014) Pelagic Sargassum community change over a 40-year period: temporal and spatial variability. Mar Biol 161:2735-2751. https://doi.org/10.1007/ s00227-014-2539-y

Lalli CM, Gilmer RW (1989) Pelagic Snails. Stanford University Press

Larson RJ (1980) The medusa of Velella velella (Linnaeus, 1758) (Hydrozoa, Chondrophorae). J Plankton Res 2:183-186

MacNamara R, McCarthy TK (2012) Size-related variation in fecundity of European eel (Anguilla anguilla). ICES J Mar Sci 69:1333-1337. https://doi.org/10.1093/icesjms/fss123

Parker DM, Cooke WJ, Bulletin GBF, 2005 (2003) Diet of oceanic loggerhead sea turtles (Caretta caretta) in the central North Pacific. Fish Bull Natl Ocean Atmos Adm 103:142-152

Pendleton L, Krowicki F, Strosser P, Hallett-Murdoch J (2014) Assessing the economic contribution of marine and coastal ecosystem services in the Sargasso Sea. Nicholas Institute for Environmental Policy Solutions, Duke University. https://nicholasinstitute.duke. edu/sites/default/files/publications/ni_r_14-05_full_pdf.pdf

Purcell JE (1984) Predation on larval fish by Portuguese man of war, Physalia physalis. Mar Ecol Prog Ser 19:189-191

Purcell JE, Clarkin E, Doyle TK (2012) Foods of Velella velella (Cnidaria: Hydrozoa) in algal rafts and its distribution in Irish seas. Hydrobiologia 690:47-55. https://doi.org/10.1007/ s10750-012-1052-x
Ross RM, American LQ (1990) Mating-behavior and spawning in two neustonic nudibranchs in the family Glaucidae. Am Malacol Bull 8:61-66

Siuda A (2011) Summary of Sea Education Association Long-term Sargasso Sea Surface Net Data

Thompson TE, McFarland ID (1967) Observations on a collection of Glaucus from the Gulf of Aden with a critical review of published records of Glaucidae (Gastropoda, Opisthobranchia). J Crustac Biol 178:107-123

Trott TM, Mckenna SA, Pitt JM et al (2011) Efforts to enhance protection of the Sargasso Sea. Proceedings of the 63rd Gulf and Caribbean Fisheries Institute 282-288

Wedemeyer-Strombel KR, Balazs GH, Johnson JB et al (2015) High frequency of occurrence of anthropogenic debris ingestion by sea turtles in the North Pacific Ocean. Mar Biol 162:2079-2091. https://doi.org/10.1007/s00227-015-2738-1

Wilson DP (1956) A contribution to the biology of Ianthina janthina (L.)

Winston JE (1982) Drift plastic — an expanding niche for a marine invertebrate? Prog Oceanogr 13:348-351. https://doi.org/10.1016/ 0025-326X(82)90038-8

Witherington B (2002) Ecology of neonate loggerhead turtles inhabiting lines of downwelling near a Gulf Stream front. Mar Biol 140:843-853. https://doi.org/10.1007/s00227-001-0737-x

Woltereck R (1904) Ueber die Entwicklung der Velella aus einer in der tiefe vorkommenden Larve. Fischer

Publisher's note Springer Nature remains neutral with regard to jurisdictional claims in published maps and institutional affiliations. 